\title{
Transition of Care for Adults with Congenital Urological Conditions
}

\author{
Laura M. Martinez, MD* \\ Gennady Slobodov, MD \\ Jennifer Lewis, APRN \\ Emily Haddad, LCSW \\ Dominic Frimberger, MD
}

\author{
Address \\ *University of Oklahoma Health Sciences Center, 920 Stanton L. Young Blvd, WP \\ 3150, Oklahoma City, OK, 73104, USA \\ Email: laura-martinez@ouhsc.edu
}

Published online: 18 January 2016

(C) Springer International Publishing AG 2016

This article is part of the Topical Collection on Pediatric Urology

Keywords Urology $\cdot$ Neurogenic bladder $\cdot$ Congenitalism $\cdot$ Spina bifida $\cdot$ Urinary tract reconstruction $\cdot$ Transition care

\section{Opinion statement}

Patients with congenital urologic conditions require complex chronic care from birth to adulthood. Early in life, these patients may establish close relationships with their specialized pediatric providers and commonly undergo complex reconstructive procedures. When these patients approach adulthood, they are faced with an informal transition to an adult urologist and may become lost to follow-up. Goals of care during this transition period must be identified and addressed by these patients' future providers. The concept of transition care is now emerging in urology. We propose that the most effective model for successful transfer of care involves joint involvement from pediatric and adult providers in the same setting.

\section{Introduction}

Many diseases affect the genitourinary tract with need for lifelong care and management. These include congenital conditions (spina bifida, bladder exstrophy, posterior urethral valves, anorectal malformations, cloacal malformations), trauma (spinal cord or brain injury, pelvic surgery), and neoplasm (rhabdomyosarcoma, spinal and brain tumors). Spina bifida is the most common cause of neurogenic bladder in the pediatric population. Due to the advent of antibiotics after the WWII era, ventriculoperitoneal shunts in the 1950s, and intermittent catheterization in the 1970s, $85-90 \%$ of children with spina bifida are now surviving into adulthood [1]. Based on the epidemiology of congenital urologic disease, an estimated 4363 babies were born 
in the USA in 2012 who will need transitional care when they reach adulthood (Fig. 1).

In 2002, the American Academy of Pediatrics, the American Academy of Family Physicians, and the American College of Physicians-American Society of Internal Medicine released a joint consensus statement on the importance of health care transitions for young adults with special health care needs [2]. Transitional care in urology has been a topic of growing interest on a national level; the NIH hosted a forum in February 2015 addressing the research needs for effective transition in lifelong care of congenital urologic conditions, and the American Urologic Association hosted its first Congenitalism forum at the 2015 Annual Meeting.

Goals of care for patients with congenital urologic conditions include preservation of renal function, maintenance of continence, and assistance with sexual function [3]. In one study, active urologic issues upon presentation to adult spina bifida clinics included urinary incontinence (52\%), recurrent urinary tract infection $(34 \%)$, catheterization difficulty $(12 \%)$, and calculi (9\%) [4].

\section{Clinical aspects of care}

\section{Preserving renal function}

The primary medical focus of urologic care in this population is renal preservation, often involving the management of hydronephrosis and a hostile bladder environment. Causes of nephropathy include obstructive uropathy, bladder dysfunction, and urinary tract infection [5]. In patients with myelomeningocele, kidney function can deteriorate without early aggressive bladder management. In a prospective cohort of 117 spina bifida patients born between 1963 and 1971, $54 \%$ died by age 35 and $32 \%$ of the deaths were due to ESRD [6]. Regular urologic care of these patients often involves evaluation with videourodynamics, initiation of clean intermittent catheterization, anticholinergic medications, and surgery if necessary. In patients with deteriorating renal function, obstructive uropathy or sustained high bladder pressures should be followed closely and evaluated with imaging and urodynamic studies.

Of note, patients with myelomeningocele may have considerable change in their lower urinary tract function during puberty, potentially leading to elevated pressures and worsening of hydronephrosis [5]. Specifically, maximum

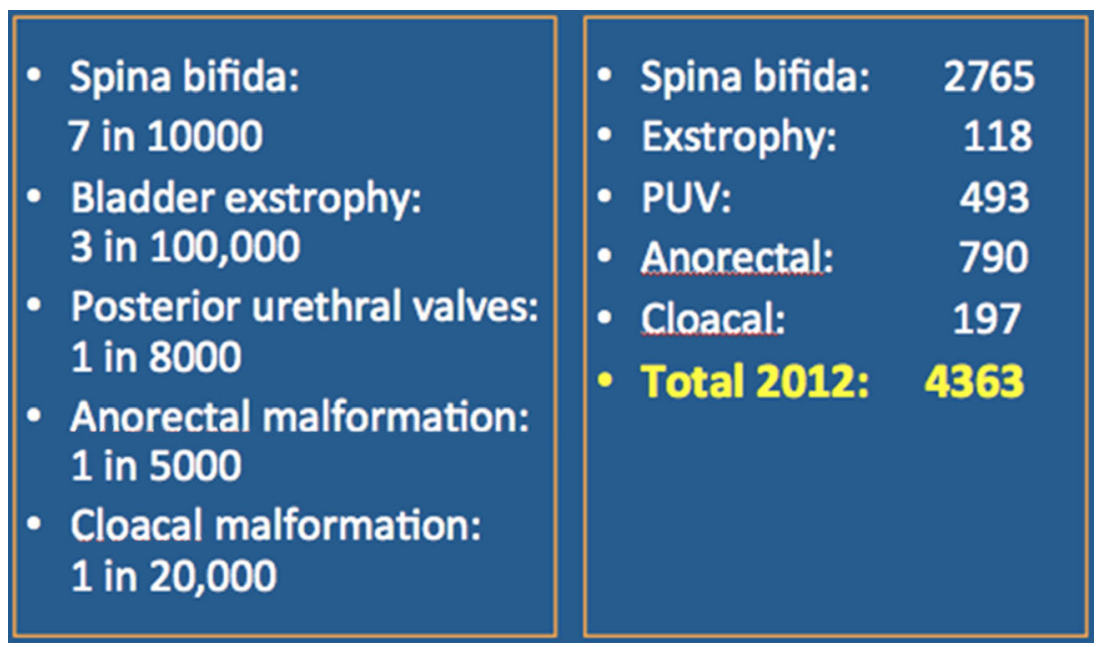

Fig. 1. Estimated incidence of congenital urologic diseases, based on 3.95 million births in 2012 . 
cystometric capacity, maximum detrusor pressure, and leak point pressure tend to increase with puberty [7]. For example, a previously incontinent patient who becomes dry without any changes in management may need to be evaluated for a threatening change in bladder dynamics.

Patients with congenital obstructive uropathy (i.e., posterior urethral valves) may have irreversible damage to the bladder and kidneys in utero [7]. Poor intrauterine indices, such as early prenatal diagnosis and oligohydramnios, are predictors of poor prognosis from renal function perspective [5]. Progressive renal dysfunction is primarily nephrologic in origin, but bladder dysfunction in adolescence can be an exacerbating factor that requires close urologic follow-up [7]. Despite valve ablation, $32 \%$ of patients with posterior urethral valves develop end-stage renal disease and will eventually require renal transplant despite early urologic management [8]. Proper evaluation and management of the posterior urethral valve bladder may impact the transplant graft survival.

\section{Conservative bladder management}

As noted previously, aggressive early bladder management is the cornerstone of preserving renal function, as well as to achieve continence. At our institution, newborns with spina bifida are started on clean intermittent catheterization at birth and generally continue until their first urodynamic study at 2 months of age. Patient and family comfort with catheterization are paramount to achieving compliance. Catheterization is not only critical in regard to protecting renal function, it is also important in maintaining continence. Based on 2481 participants in the CDC National Spina Bifida Patient Registry, $64 \%$ of patients were incontinent and $36 \%$ continent; $95.8 \%$ of those continent use clean intermittent catheterization [9].

Issues with chronic catheterization include urethral trauma, which may lead to stricture, perforation, or stenosis [7]. Additionally, bacterial colonization of the bladder occurs with repeated catheterization that often complicates the diagnosis of urinary tract infections in these patients. Asymptomatic bacteriuria does not require antibiotic therapy, but these patients may be treated with antibiotics by providers who are unfamiliar with their history.

Antimuscarinic medication is the cornerstone of pharmacologic management of neurogenic bladder and has been shown to decrease overactivity, decrease maximum detrusor pressure, and improve compliance and capacity. Long-term use of oxybutynin has not been shown to have enduring adverse effects [7]. Intravesical injection of botulinum toxin (Botox) is FDA approved for treatment of adults with urinary incontinence due to neurogenic bladder refractory to conservative therapy. Studies in the pediatric population have also shown efficacy, with improved compliance, capacity, and continence [10]. The duration of efficacy is typically 6-9 months, and thus requires repeat injections, and long-term efficacy has not been shown to decrease with repeated injections [11]. In general, intravesical Botox may be used as a means of avoiding or delaying reconstructive bladder surgery, such as augmentation.

When conservative measures fail, patients may undergo complex reconstructive surgeries to protect renal function and achieve continence. These procedures include bladder augmentation, catheterizable channels, and bladder neck 
reconstruction. Familiarity with these procedures and their complications is important for care into adulthood. Despite excellent outcome numbers in publication, surgical failures do occur, and many of these will need to be addressed in adult clinics.

The standard technique of bladder augmentation involves creation of a high capacity, low pressure reservoir. We commonly use the terminal ileum 10-15 $\mathrm{cm}$ proximal to the ileocecal valve, detubularize the ileum, and perform anastomosis to the bivalved bladder plate. Catheterizable channels can be created in a variety of methods, with excellent continence rates: appendicovesicostomy-97-98 \% continent $[12,13]$, serosal trough-92 \% [14], robotic Mitrofanoff-100\% continent [15]. Methods of bladder neck surgery include the Young-Dees-Leadbetter repair (most commonly in exstrophy patients), bladder neck ligation, fascial sling, and bulking agent injection.

In addition to the aforementioned bladder procedures, the Malone antegrade continence enema is another surgery that can improve quality of life for patients with both bladder and bowel dysfunction. Of the patients in the CDC National Spina Bifida Patient Registry, $61 \%$ were incontinent of stool [9]. In a questionnaire-based study of 65 patients at one institution, the highest level of satisfaction was reported by $89 \%$ with significant improvements in social confidence and hygiene [16].

Complications related to these surgeries include metabolic derangements, accumulation of mucus requiring irrigation, formation of bladder/reservoir stones, and stomal complications. An additional consideration in the adult population is the risk of malignancy in the reconstructed urinary system, which has been estimated to be $1.2 \%$ and as high as $5.5 \%$ in those with gastrocystoplasty [17]. The majority of malignancies associated with bladder reconstruction are adenocarcinoma; however, there are reports of transitional and squamous cell carcinomas [18]. Notably, a long-term comparative study by Higuchi et al. found no difference in time point of initial presentation, stage, mortality rate, median survival, or incidence of bladder cancer in patients with bladder augmentation or without [19]. There are currently no formal guidelines for cancer screening in this population; routine annual cystoscopy is not recommended without a specific indication, such as hematuria, change in rate or severity of UTIs, or unexplained pain [5]. A rare exception to this is ureterosigmoidostomy, with $22 \%$ risk of neoplasia at anastomosis at 20 years; it is recommended that these patients have annual flexible sigmoidoscopy beginning 10 years postoperatively [20].

Overall, augmentation numbers are declining in the USA. In 2000, 792 augmentation cystoplasties were performed, which decreased by $25 \%$ to 595 in 2009 [21]. There are many possible reasons for this decline, including a decrease in the affected population with the advent of prenatal management, change in management favoring more conservative approaches, new techniques such as intravesical Botox and bladder neck bulking, and finally, delay of definite surgery. This raises the question of the increased potential for renal failure in the future and need for surgery later in adulthood. 
Nephrolithiasis is also prevalent in this population and can be associated with deterioration of renal function. The etiology of stone disease is multifactorial, caused by urinary stasis, immobilization, chronic catheterization, and recurrent urinary tract infections. A recent retrospective review of hospital admissions for renal and ureteral stones using the NIS database found that patients with spina bifida were more likely to be younger, have renal stones, undergo percutaneous nephrolithotomy, and had a higher risk of in-hospital postoperative complications compared to those without spina bifida [22].

Our institution performed a retrospective review of 21 adult neurogenic bladder patients who underwent percutaneous nephrolithotomy (PCNL) [23]. The majority of these patients had neurogenic bladder due to spinal cord injury (66.7 \%). Several patient and stone-related factors made PCNL more challenging in these patients, including severe scoliosis in $47.6 \%$, preoperative bacteriuria in $90.5 \%$, and complete staghorn in $46.2 \%$ of renal units. Each patient underwent two PCNLs, on average; the stone-free rate was only $53.8 \%$ after one PCNL and improved to $88.5 \%$ after three PCNLs. Complications included urosepsis in three patients (14.3\%) and bleeding requiring transfusion in six patients $(28.6 \%)$.

Patients with prior reconstructive surgery are also prone to bladder/reservoir stone formation. A method of percutaneous cystolithotomy using laparoscopic and endourologic techniques was developed at our institution [24]. Percutaneous access obtained under cystoscopic vision with a 10-mm laparoscopic trocar through the patient's previous suprapubic cystostomy scar, calculi manipulated in laparoscopic entrapment bag, 30-F Amplatz sheath is introduced and ultrasonic lithotripsy performed via a nephroscope. At the time of our study, this technique was used to treat stones up to $7 \mathrm{~cm}$ with $100 \%$ stone-free rate.

Sexuality and fertility are not commonly discussed in the pediatric urology setting [25], but sexual health emerges as an important issue as patients transition into adulthood. There is limited information regarding sexual function in the neurogenic bladder population, but these patients appear to have high rates of sexual dysfunction [26]. In a cohort of 76 adult patients with spina bifida, only $24 \%$ patients were sexually active in the last 2 months, with sexual activity more likely in patients with more caudal levels neurologic impairment [26, 27]. Erectile dysfunction is common in the spina bifida population: $75 \%$ in one study of International Index of Erectile Function (IIEF) scores among myelomeningocele patients [28].

Patients with other urologic conditions may also be affected later in life with regard to sexual function and fertility. Those with prior penile reconstructive surgery, such as hypospadias or epispadias repair, may require revision for corporeal scarring or development of chordee [5]. Additionally, male patients with a history of exstrophy may have problems with ejaculatory function, and thus fertility, due to the absence of the bulbocavernosus or ejaculatory duct obstruction from prior bladder neck surgery [5]. Pregnancy is often high risk in female patients with a history of exstrophy and complex bladder reconstruction, and delivery should involve a coordinated care plan with urology coverage if needed [29]. 


\begin{tabular}{|c|c|c|c|c|}
\hline Stage & Age & Providers & Setting & Description \\
\hline T1 & $14-16$ & Pediatric only & Pediatric clinic & $\begin{array}{l}\text { Begin transition readiness } \\
\text { Literature provided of packet of } \\
\text { introduction and educational material }\end{array}$ \\
\hline T2 & $>16$ & Pediatric, introduction to adult providers & Pediatric clinic & $\begin{array}{l}\text { Assessment of readiness continues; } \\
\text { evaluation of when approximate } \\
\text { transition to occur } \\
\text { Introduction of sexual questionnaires }\end{array}$ \\
\hline T3 & $>16$ & $\begin{array}{l}\text { Adult, pediatric providers available } \\
\text { if needed }\end{array}$ & Pediatric clinic & $\begin{array}{l}\text { Continued evaluation of readiness for } \\
\text { transition to adult clinic }\end{array}$ \\
\hline T4 & $>16$ & Adult only & Adult clinic & $\begin{array}{l}\text { Transition complete } \\
\text { Feedback for transition process }\end{array}$ \\
\hline
\end{tabular}

\section{Conclusions}

Transition clinics are designed for "purposeful, planned movement of adolescents and young adults with chronic physical and medical conditions from child-centered to adult-oriented health-care systems" [30]. There have been many reports on transition clinics in various fields, but they have been successful in only $47-65 \%$ [30].

Inherent problems of transition include compliance and dependence. The comprehensive care of patients requiring transition includes consideration of quality of life, social life, continence, physical activity, and physical health. During childhood and adolescence, parents organize their child's health care, manage disease, and make treatment decisions. The patients often rely on their doctors and caregivers to take care of all aspects of their health care. In this neurogenic population, $95 \%$ of youth and $61 \%$ of adults are still living with their parents [31]. As such, patients are often reluctant to leave the familiar setting of their pediatric centers due to the comfort of longstanding relationships forged with their pediatric providers and staff.

There are also provider-related obstacles, such as reluctance of pediatric providers to relinquish care of their patients and difficulty in finding adult providers who are equally interested [32]. Additionally, adult providers may lack familiarity with issues specific to this population, such as reconstructive surgeries and their complications. The increasing patient workload to adult urology providers due to an aging American population is another competitor to transition of some of the more complicated urologic conditions.

Communication and early exposure to adult care have been identified as key for successful transfer. Many transition models support early introduction to the adult provider $[1,25,33]$. This can be accomplished in a joint clinic where adult and pediatric providers are both present. Our institution has established the REACH clinic, a joint transition clinic which is held at the pediatric facility (http://reach-clinic.org). The concept encompasses classification and 
methodical progression to the ultimate graduation to adult urology health care setting. Prior to each visit, the patient is assigned a "T-stage," representing their readiness for transition on a scale from 1 to 4 (Table 1); this is based on age as well as our readiness assessment tool. Adult providers are gradually introduced as the patient advances through the T-stages; at stage T4, they have fully transitioned to the adult clinic. There remains a challenge where adult and pediatric providers are unable to see patients jointly at the same institution to replicate such a well-designed transition process.

\section{Compliance with ethical standards}

\section{Conflict of interest}

Laura M. Martinez declares that she has no conflict of interest.

Gennady Slobodov declares that he has no conflict of interest.

Jennifer Lewis declares that she has no conflict of interest.

Emily Haddad declares that she has no conflict of interest.

Dominic Frimberger has acted as consultant for Astellas and Salix outside of the submitted work.

Human and animal rights and informed consent

This article does not contain any studies with human or animal subjects performed by any of the authors.

\section{References and Recommended Reading}

1. Mukherjee S. Transition to adulthood in spina bifida: changing roles and expectations. Sci World J. 2007;7:1890-5.

2. American Academy of Pediatrics; American Academy of Family Physicians; American College of PhysiciansAmerican Society of Internal Medicine. A consensus statement on health care transitions for young adults with special health care needs. Pediatrics. 2002;110(6 pt 2):1304-6.

3. Szymanski KM, et al. Current opinions regarding care of the mature pediatric urology patient. J Pediatr Urol 2015 June. Pii: S1477-5131(15)00223-5 (epub ahead of print).

4. Summers SJ et al. Urologic problems in spina bifida patients transitioning to adult care. Urology. 2014;84(2):440-4.

5. Wood D. Adolescent urology: developing lifelong care for congenital anomalies. Nat Rev Urol. 2014;11:28996.

6. Hunt GM, Oakeshott P. Outcome in people with open spina bifida at age 35: prospective community based cohort study. BMJ. 2003;326(7403):1365-6.

7. Woodhouse CRJ et al. Adult care of children from pediatric urology. J Urol. 2012;187:1164-71.

8. Holmdahl G, Sillén U. Boys with posterior urethral valves: outcome concerning renal function, bladder function and paternity at ages 31 to 44 years. J Urol. 2005; 174:1031.

9. CDC National Spina Bifida Registry http://www.cdc. gov/ncbddd/spinabifida/nsbprregistryfindings.html.

10. Altaweel W, Jednack R, Bilodeau C, et al. Repeated intradetrusor botulinum toxin type $\mathrm{A}$ in children with neurogenic bladder due to myelomeningocele. J Urol. 2006;175:1102.

11. Schulte-Baukloh H, Knispel HH, Stolze T, et al. Repeated botulinum-A toxin injections in treatment of children with neurogenic detrusor overactivity. Urology. 2005;66:865.

12. Cain MP et al. Appendicovesicostomy and newer alternatives for the Mitrofanoff procedure: results in the last 100 patients at Riley Children's Hospital. J Urol. 1999;162(5):1749-52.

13. Clark T et al. Factors that influence outcomes of the Mitrofanoff and Malone antegrade continence enema in reconstructive procedures in children. J Urol. 2002;168:1537-40.

14. Baradaran $\mathrm{N}$ et al. Using a serosal trough for fashioning a continent catheterizable stoma: technique and outcomes. BJU Int. 2013;111(5):828-33.

15. Gundeti MS et al. Paediatric robotic-assisted laparoscopic augmentation ileocystoplasty and Mitrofanoff appendicovesicostomy (RALIMA): feasibility of and 
initial experience with the University of Chicago technique. BJU Int. 2011;107(6):962-9.

16. Yerkes EB et al. The Malone antegrade continence enema procedure: quality of life and family perspective. J Urol. 2003;169(1):320-3.

17. North AC, Lakshmanan Y. Malignancy associated with the use of intestinal segments in the urinary tract. Urol Oncol. 2007;25:165-7.

18. Austin JC. Long-term risks of bladder augmentation in pediatric patients. Curr Opin Urol. 2008;18:408.

19. Higuchi TT, Granberg CF, Fox JA, et al. Augmentation cystoplasty and risk of neoplasia: fact, fiction and controversy. J Urol. 2010;184:2492.

20. Cairns SR, Scholefield JH, Steele RJ, et al. Guidelines for colorectal cancer screening and surveillance in moderate and high risk groups (update from 2002). Gut. 2010;59:666.

21. Schlomer BJ et al. National trends in augmentation cystoplasty in the 2000s and factors associated with patient outcomes. J Urol. 2013;190(4):1352-7.

22. Wang HH et al. Complications of surgical management of upper tract calculi in spina bifida patients: analysis of nationwide data. J Urol. 2015;193(4):1270-4.

23. Nabbout PS et al. Percutaneous nephrolithotomy in spinal cord neuropathy patients: a single institution experience. J Endourol. 2012;26(12):1610-3.

24. Lam PN et al. Percutaneous cystolithotomy of large urinary-diversion calculi using a combination of laparoscopic and endourologic techniques. J Endourol. 2007;21(2):155-7.
25. Van der Toorn $\mathrm{M}$ et al. Needs of children with a chronic bladder in preparation for transfer to adult care. J Ped Urol. 2013;9:509-15.

26. Lee NG et al. The effect of spinal cord level on sexual function in the spina bifida population. J Pediatr Urol. 2015;11(3):142.

27. Lassman J et al. Sexual function in adult patients with spina bifida and its impact on quality of life. J Urol. 2007;178:1611-4.

28. Game X et al. Evaluation of sexual function in young men with spina bifida and myelomeningocele using the International Index of Erectile Function. Urology. 2006;67(3):566-70.

29. Deans R et al. Reproductive outcomes in women with classic bladder exstrophy: an observational crosssectional study. Am J Obstet Gynecol. 2012;206(6):496.

30. Reiss J, Gibson R. Health care transition: destination unknown. Pediatrics. 2002;110(6):1307-14.

31. Young NL et al. The transition study: a look at youth and adults with cerebral palsy, spina bifida, and acquired brain injury. Phys Occ Ther Pediatr. 2006;26(4):25-45.

32. Binks JA, Barden WS, Burke TA, et al. What do we really know about the transition to adult-centered health care? A focus on cerebral palsy and spina bifida. Arch Phys Med Rehabil. 2007;88:1064.

33. Timberlake MD et al. Identification of adolescent and adult patients receiving pediatric urologic care and establishment of a dedicated transition clinic. J Pediatr Urol. 2015;11(2):62. 